\title{
Familiares de usuários vivenciando a transformação do modelo assistencial psiquiátrico ${ }^{1}$
}

\author{
Marli Benedita Santos Ribeiro \\ Universidade Sagrado Coração - Bauru/SP \\ Sueli Terezinha Ferreira Martins \\ Luiz Roberto de Oliveira \\ Universidade de São Paulo - Botucatu
}

\begin{abstract}
Resumo
A assistência à saúde mental brasileira passa por uma transformação do modelo psiquiátrico tradicional, centrado na exclusão da pessoa com transtorno mental, para a criação de uma rede de serviços substitutivos na comunidade. Assim, provoca-se uma mudança no papel dos familiares, que são chamados a participar das estratégias de cuidado, reabilitação e inclusão social. Este ensaio visa discutir a opinião dos familiares de usuários da Associação Arte e Convívio, Botucatu-SP, Brasil, sobre aspectos relacionados à sua realidade e à convivência com o transtorno mental, pois a Associação não consegue contar com a participação dos familiares em suas atividades. A metodologia utilizada foi a de história oral. Constatou-se sobrecarga econômica, social e emocional decorrentes do preconceito e da convivência com a pessoa com transtornos mentais. Conclui-se que a AAC, para superar as dificuldades de envolver os familiares em suas atividades, deve dar atenção às questões de fundo econômico e social.
\end{abstract}

Palavras-chave: relações familiares; inclusão social; saúde mental; organização civil

\begin{abstract}
Users'relatives experiencing changes in the psychiatric care model. Centered on the exclusion of individuals with mental disorders, the traditional psychiatric model of mental health care in Brazil has undergone changes for the creation of a network of substitutive services in the community. Therefore, a change is made to the role played by relatives, who are called to participate in care, rehabilitation and social inclusion strategies. This assay aims at discussing the opinion of relatives of Associação Arte e Convívio (AAC) users in Botucatu-SP, Brazil as regards the aspects related to their reality and experience concerning mental disorders, since such relatives have not participated in AAC activities. The oral account methodology was used, and the following aspects were found to be part of the relatives' everyday lives: economic, social and mental overload as a result of prejudice and living with a person who has mental disorders. It was concluded that for AAC to overcome the difficulties of involving relatives in their activities, it will be necessary to heed attention to economic and social issues.
\end{abstract}

Keywords: family relationships; social inclusion; mental health; civil organization

$\mathrm{O}$ Brasil, na área da saúde pública, está buscando a implantação de modelos de atenção que extrapolem a assistência médico-curativa, em que a compreensão da saúde não se limite à ausência de doença. Nestes modelos, a promoção da saúde ganha destaque e as ações incidem sobre fatores socioeconômicos determinantes da doença, procurandose levar em conta as condições e a qualidade de vida da população.

$\mathrm{Na}$ área da saúde mental, nas últimas décadas, vem acontecendo uma transformação da assistência, com base na reforma psiquiátrica, que se reflete numa tentativa de rompimento com o modelo asilar (cujo fundamento é a exclusão social), para a criação de uma rede de serviços substitutivos ao hospital psiquiátrico, tais como: centros de atenção psicossocial (CAPS), hospitais-dia, leitos psiquiátricos em hospitais gerais, ambulatórios, centros de convivência, oficinas de geração de renda, serviços residenciais terapêuticos, entre outros. Mais recentemente, com a publicação de alguns documentos pelo Ministério da Saúde, e com uma longa história de práticas de saúde mental na atenção primária, há a preocupação de garantir um diálogo mais estreito da área de saúde mental com a atenção básica (Ministério da Saúde, 2003, 2008).

As pessoas que foram diagnosticadas como portadoras de transtornos mentais graves (basicamente, esquizofrenia e transtornos do humor), em sua maioria, apresentam problemas severos e persistentes, com restrição ou carência de habilidades 
para realizar atividades cotidianas, tais como atividades produtivas, de autocuidado e sociais, resultando na anulação do seu poder contratual e na perda ou diminuição da sua autonomia e independência. Nestes casos, como salientam Alves e Guljor (2004) e Kinoshita (1996), o desafio do trabalho é aumentar o

da Associação Arte e Convívio (AAC), uma organização civil, sem fins lucrativos que congrega usuários, familiares e trabalhadores dos serviços de saúde mental do município de Botucatu, São Paulo, Brasil.

\section{A família diante da transformação do modelo assis- tencial psiquiátrico}

A estrutura familiar não é algo universal, natural ou biológico, e sim produto da determinação histórico-social. Sua função tem sido assegurar a reprodução dos seres humanos na dimensão biológica, socioeconômica e ideológica, isto é, ela transmite aos seus membros como se comportar dentro e fora das relações familiares, sendo, portanto, formadora do cidadão (Campaña, 1995; Reis, 1994).

A participação da mulher no mercado de trabalho, intensificada nas últimas décadas, dependendo da classe social a que pertence, implica superposição, pois ela geralmente já assume funções de esposa, dona-de-casa e mãe. Quando há uma pessoa com transtorno mental grave em idade adulta e dependente na família, o cuidado também pode representar mais uma sobrecarga física e emocional. As pesquisas mostram que a mulher (mãe, esposa, irmã etc.) é prioritariamente quem assume o cuidado do familiar com transtorno mental (Gonçalves \& Sena, 2001; Rosa, 2003; Souza \& Scatena, 2005).

A participação da família no tratamento das pessoas com transtornos mentais (PTM) ${ }^{2}$ é ainda bastante recente, pois até o final da década de 1970 este tratamento era basicamente asilar o que proporcionava um afastamento entre a PTM e a família. Quando o vínculo familiar era rompido devido aos longos períodos de internação, o hospital psiquiátrico assumia a PTM, o que resultou no grande número de pessoas que moram nos hospitais psiquiátricos atuais.

Com a permanência da pessoa com transtorno mental na comunidade, faz-se necessário o planejamento de estratégias públicas de atenção às famílias, pois elas passam a ser responsabilizadas, na maioria dos casos, a prover o cuidado socioeconômico e emocional do familiar adoecido. A experiência profissional no município onde a pesquisa relatada foi realizada demonstra que muitas famílias por encontrarem dificuldades na convivência com a pessoa adoecida mentalmente, têm procurado soluções como: isolá-los em quartos separados da casa, colocálos em hotéis, casas de repouso ou pensões, nesses casos, quando a família tem um poder aquisitivo melhor. No caso de idosos, o Relatório de Inspeção a Instituições de Longa Permanência para Idosos (Conselho Federal de Psicologia/Ordem dos Advogados do Brasil, 2008), indica que parte dos usuários das vinte e duas instituições avaliadas é formada por pessoas com transtornos mentais e que necessitam de cuidados nesta área.

Deste modo, no processo da Reforma Psiquiátrica, a família da pessoa com transtorno mental adquire papel central, mais como parceira e apoio para a reabilitação do que como principal responsável pelo sofrimento psíquico, como era considerada em outros momentos históricos (Amarante, 1996; Dalla Vecchia \& Martins, 2006; Moreno, 2000; Rosa, 2003).

Rosa (2003), ao falar sobre a relação da família com a PTM, a partir das discussões e reflexões suscitadas pelo Movimento Nacional da Luta Antimanicomial e a Reforma Psiquiátrica, afirma que nos anos 1990 surge "uma pluralidade de representações sobre suas relações com a PTM a partir do quadro de intervenção ou do papel que se lhe atribui na realidade social que aponta para a família em pelo menos cinco direções" (p. 80), a saber: (1) como um "recurso" como outro qualquer; como um "lugar" de convivência da PTM, desde que os laços relacionais possam ser mantidos ou reconstruídos; (2) como "sofredora", pois a convivência com uma PTM a influencia e, desse modo, precisa ser "tratada", assistida, recebendo suporte social e assistencial; (3) como um "sujeito" da ação: sujeito coletivo que se organiza em associações específicas; sujeito avaliador dos serviços; (4) construtor da cidadania da PTM e (5) como "provedora de cuidado", já que, em geral, é a família o principal agente mediador entre a PTM e a sociedade, na medida em que os serviços de saúde tendem a atuar sobre os momentos de crise, não prestando cuidados contínuos e cotidianos.

A autora alerta, ainda, que com o neoliberalismo reorientando as políticas públicas desde a década de 1970, muitas funções anteriormente assumidas pelo Estado são devolvidas à família ou exige-se que ela as assuma. Com isso, a família sobrecarrega-se com várias tarefas para as quais não se encontra preparada, entre elas, o cuidado da PTM. Além disso, há a sobrecarga econômica (Rosa, 2003).

A importância da família no cuidado à pessoa com transtorno mental, principalmente àquelas com transtornos graves e severos, com pouca autonomia, que têm necessidade de apoio contínuo, é evidente. No entanto, apesar disso, ela não tem recebido a devida atenção pelas políticas públicas de saúde mental.

Historicamente, nossa sociedade aprendeu a pensar a loucura/ doença mental como relacionada ao asilo, suscetível de reclusão, negatividade, desumanidade e, sobretudo, periculosidade social (Giovanela \& Amarante, 1994). Esta estreita ligação entre doença mental e periculosidade vem mantendo a visão preconceituosa de nossa sociedade em relação ao transtorno mental, fazendo com que um grande número de pessoas que necessita de atenção na área de saúde mental passe por um processo de marginalização afetiva e social, que tem sua extensão na família. As famílias dessas pessoas vivem, portanto, uma realidade de preconceito e exclusão, o que ocasiona muita dor e sofrimento psíquico (Melman, 2001).

Merece atenção, também, a forma como o Estado brasileiro vem conduzindo a redução dos leitos e o fechamento dos hospitais psiquiátricos. Não se tem observado a necessária e efetiva articulação com a abertura e funcionamento de uma rede substitutiva de serviços que seja mais do que uma alternativa ao manicômio. Faz-se necessário que estes serviços tenham uma atuação territorializada, isto é, que seja uma rede regionalizada e hierarquizada de serviços capaz de assumir a completa responsabilidade pela atenção ao sofrimento psíquico dos sujeitos residentes nas respectivas áreas de abrangência. Para essa territorialização da assistência da saúde mental é necessário dimensionar o campo clínico e diversificar as linguagens e os 
discursos, procurando multiplicar as formas de inter-relação com outros saberes e disciplinas, que englobem as necessidades das pessoas com transtornos mentais no âmbito do trabalho, da moradia, do direito, do lazer e da cultura (Melman, 2001).

Um dos dispositivos utilizados para lidar com questões de interesse dos usuários e familiares é a organização em associações civis. A primeira associação brasileira com a participação de usuários, familiares e trabalhadores em saúde mental foi a Sociedade de Serviços Gerais para a Integração pelo Trabalho (SOSINTRA), que atua desde o final da década de 1970 no Rio de Janeiro. Nas décadas seguintes, há um aumento significativo na formação de organizações como essa e, desde 1988, muitas destas entidades vêm participando efetivamente dos projetos de criação de novas práticas e modalidades de cuidado e atenção, assim como da luta pela transformação do modelo hospitalocêntrico (Amarante, 2000; Souza, 2001).

No município de Botucatu, estado de São Paulo, em 1995, a partir da iniciativa de profissionais da saúde mental, usuários, familiares e líderes comunitários, foi estruturada uma organização civil, a Associação Arte e Convívio (AAC), para atender usuários dos serviços de saúde mental com diagnósticos de transtornos mentais severos e persistentes e que estão excluídos dos seus direitos sociais. A responsabilidade pela AAC cabe a uma equipe formada por: quatro assistentes sociais, três terapeutas ocupacionais, um psicólogo e um auxiliar de serviços gerais que se dividem entre funções técnicas e administrativas. Por procurar uma forma de funcionamento horizontalizada, os profissionais que trabalham nesta organização exercem funções baseadas na interdisciplinaridade, e pode-se dizer que são facilitadores, procurando atender as necessidades dos usuários e possibilitar a produção de novas subjetividades. Trabalham no planejamento, execução e coordenação dos projetos, estimulando os usuários a compartilharem e serem parceiros dos projetos e decisões, bem como a se conscientizarem de seus direitos de cidadãos (Ribeiro, 2003).

A AAC atende semanalmente, mais ou menos, quarenta usuários. Procura instrumentalizar os usuários associados e usuários dos serviços de saúde para o exercício do controle social, por meio da informação e participação em conselhos nos diversos níveis de gestão. Com a organização de oficinas temáticas, possibilita que usuários fora do mercado de trabalho experimentem atividades autônomas e geradoras de renda baseadas em conceitos solidários de produção, respeitando as singularidades. Na parceria com órgãos de formação profissional, busca qualificar as pessoas que têm interesse e habilidade para a inserção no mercado formal ou informal de trabalho. Além disso, caracteriza-se por ser um centro de convivência e atividades de expressão artística (Associação Arte e Convívio, 2006). Portanto, a Associação procura promover mudanças na atitude dos usuários em relação ao trabalho, ao convívio social e à criatividade, ampliando sua capacidade de contratualidade e lhes dá novo sentido às suas vidas.

Contudo, desde o início das atividades da Associação, a equipe não tem conseguido o envolvimento das famílias dos usuários nesse processo. $\mathrm{O}$ comparecimento de familiares nas reuniões organizadas tem sido irrisória. Para a equipe responsável pela Associação, o movimento de transformação individual e a luta pelos direitos políticos e civis das PTMs necessitam do envolvimento e da participação ativa dos familiares. Impõe-se, para tanto, o conhecimento da realidade das famílias para que se proponham estratégias de aproximação e de atuação.

A presente investigação é parte de um projeto que incluiu, também, a quantificação de características sócio-demográficas dos grupos familiares da AAC. O objetivo desta pesquisa foi identificar a opinião dos familiares dos grupos de usuários da AAC sobre os seguintes aspectos relacionados à sua realidade e à convivência com o transtorno mental: história da doença; exclusão social; suporte social e modificações ocorridas na família a partir do adoecimento mental e da participação do usuário na $\mathrm{AAC}$, tendo em vista colher subsídios para uma estratégia de ação.

\section{Método}

\section{Construção do percurso metodológico}

A metodologia utilizada foi a da história oral. Segundo Queiroz (1988), esta metodologia pode coexistir com metodologias quantitativas, desde que cada uma delas seja aplicada a um momento específico da pesquisa. Para a coleta das histórias, utilizou-se a técnica de entrevista estruturada, acompanhada de anotações em diário de campo. A entrevista seguiu um roteiro previamente estabelecido, sendo que as perguntas se basearam na história de adoecimento do familiar, no sentido de entender como esta questão é relatada pelas famílias e o que elas consideram importante. Foi investigado se o transtorno mental representou uma sobrecarga econômica, emocional e social para a família e se este provocou mudanças na dinâmica interna e nas relações externas, com parentes, vizinhos, amigos. Além disso, os entrevistados que relatavam a sobrecarga familiar foram questionados se pessoas na família adoeceram em função disto e possíveis modificações ocorridas na família a partir do adoecimento mental e da participação do usuário na AAC. Algumas questões foram adaptadas do estudo de sobrecarga familiar realizado por Koga (1997).

As entrevistas foram realizadas no período de quinze dias, sendo gravadas em áudio, e ao seu final foram ouvidas pelas pessoas entrevistadas, para sua avaliação e consentimento.

As fitas gravadas foram transcritas na íntegra pela entrevistadora e, em seguida, as histórias foram analisadas por meio de fragmentação, em que se buscou separar claramente os diversos componentes, recortá-los, a fim de utilizar o que era compatível com a síntese que se buscava (Queiroz, 1988). Procurou-se agrupar os pontos comuns e divergentes em cada resposta, na sequência do roteiro, bem como salientar alguns fragmentos dos mesmos que foram considerados importantes.

A escolha dos representantes das famílias entrevistadas foi baseada em alguns dados, encontrados na primeira etapa da pesquisa, adotados como critérios de inclusão: familiares de usuários com residência em Botucatu; familiares de usuários que estavam apenas em atendimento psiquiátrico ambulatorial; que frequentaram a AAC por um período suficiente para que a família pudesse avaliar a participação (estimado em doze meses); um familiar representando cada um dos tipos de família. 
Os nomes utilizados neste estudo são fictícios para preservar a identidade dos familiares. A realização da pesquisa foi autorizada pelo Comitê de Ética em Pesquisa da Faculdade de Medicina, UNESP/Botucatu, sendo empregado o Termo de Consentimento Livre e Esclarecido, no qual se assegura ao participante o anonimato, bem como o direito de desistir de sua participação em qualquer fase do trabalho sem prejuízos à sua pessoa conforme recomenda a Resolução 196, do Ministério da Saúde/Conselho Nacional de Saúde (1996).

\section{Resultados e discussão}

Embora se tenha utilizado um pequeno número de famílias para esta fase da pesquisa, os resultados deram uma visão panorâmica da complexidade do problema e poderão nortear outras pesquisas na área. Serão apresentados a seguir os resultados mais significativos.

\section{Sobrecarga econômica, emocional e social}

Os familiares referiram as dificuldades sentidas de maneira enfática, em todos os aspectos, com grande intensidade. Um deles disse não querer nem se lembrar do que tinha passado com o familiar com transtorno mental. Quanto ao aspecto econômico, eles referiram dificuldades como se observa nos relatos: "Ah meu bem, falar das dificuldades, eu não quero nem lembrar das dificuldades, porque eu passei por tantas ..." (Isaura, M). Outros referem, ainda,

as dificuldades foram demais, muitas, primeiro porque o pai dele é assim, nos separamos, mas continuamos amigos. No principio ele dava três salários mínimos, se vê, as coisas foram mudando. As coisas foram ficando difícil, foi diminuindo o dinheiro, até chegou uma época que ele não dava (Madalena, MA).

O familiar ressalta a dificuldade financeira, indicando sobrecarga econômica. É importante retomar o fato de que,

Tabela 1

Caracterização da população pesquisada

\begin{tabular}{ccccccccc}
\hline Tipo de família & Sexo & $\begin{array}{c}\text { Idade } \\
\text { (anos) }\end{array}$ & Ocupação & $\begin{array}{c}\text { Estado } \\
\text { civil }\end{array}$ & $\begin{array}{c}\text { Relação } \\
\text { com o } \\
\text { usuário }\end{array}$ & $\begin{array}{c}\text { Sexo } \\
\text { Usuário }\end{array}$ & $\begin{array}{c}\text { Idade } \\
\text { usuário } \\
\text { (anos) }\end{array}$ & $\begin{array}{c}\text { Estado } \\
\text { civil } \\
\text { usuário }\end{array}$ \\
\hline $\begin{array}{c}\text { Conjugal } \\
\begin{array}{c}\text { Ampliada (CA) } \\
\text { Roberto }\end{array}\end{array}$ & $\mathrm{M}$ & 60 & Aposentado & casado & $\begin{array}{c}\text { PAl de } \\
\text { Belchior }\end{array}$ & $\mathrm{M}$ & 32 & solteiro \\
$\begin{array}{c}\text { Conjugal (C) } \\
\text { Elis }\end{array}$ & $\mathrm{F}$ & 16 & Estudante & solteira & $\begin{array}{c}\text { FILHA de } \\
\text { Zizi }\end{array}$ & $\mathrm{F}$ & 42 & casada \\
$\begin{array}{c}\text { Monoparental (M) } \\
\text { Isaura }\end{array}$ & $\mathrm{F}$ & 76 & Dona de casa & viúva & $\begin{array}{c}\text { MÃE de } \\
\text { Caetano }\end{array}$ & $\mathrm{M}$ & 40 & solteiro \\
$\begin{array}{c}\text { Monop. ampliada } \\
\text { (MA) Madalena }\end{array}$ & $\mathrm{F}$ & 74 & Dona de casa & divorciada & $\begin{array}{c}\text { MÃE de } \\
\text { Simone }\end{array}$ & $\mathrm{F}$ & 34 & Solteira \\
\hline
\end{tabular}

quanto ao aspecto econômico, a grande maioria das famílias atendidas na Associação encontrava-se na época da pesquisa em condição de precariedade $(93,5 \%)$, sendo que destas, $78 \%$ tinham o poder aquisitivo abaixo do mínimo necessário, ou seja, em situação de pobreza. As famílias pesquisadas estão nestas condições, ou seja, elas fazem parte dos segmentos mais frágeis e em situação de exclusão social da sociedade brasileira, fato que ocorre, segundo Ferreira (2000), porque a crise no Estado brasileiro se revela na incapacidade de produzir a pactuação de um projeto nacional que incorpore a maioria da sociedade e possibilite qualidade de vida para todos. Revela-se também na ausência de políticas públicas capazes de fazerem frente a esta crise para mitigar os efeitos dramáticos sobre essa população. A situação fica bastante agravada quando se tem que prover as necessidades de um adulto improdutivo e com necessidade de cuidados especiais e que não consegue se inserir no mercado de trabalho.

Pegoraro e Caldana (2008) citam que as dificuldades financeiras interferem nos cuidados. Complementando, Colvero, Ide e Rolim (2004) afirmam que a sobrecarga familiar se dá, também, pela dependência material, acrescentando a falta de iniciativa apresentada pelo usuário.

Quanto à caracterização socioeconômica dos usuários, eles eram adultos em idade ativa, com escolaridade média e estavam fora do mercado de trabalho (Ribeiro, 2003). Quando o paciente tem iniciativa para entrar no mercado de trabalho, enfrenta dificuldades para se manter nele, como se constata seguinte relato: "O Caetano fazia ficha, mas jamais ia trabalhar, não completava nem três meses mandavam ele embora e assim ele não conseguia mais emprego" (Isaura, M).

Segundo Melman (2001), frequentemente uma pessoa da família precisa ficar cuidando da pessoa com transtorno mental, 
o que impossibilita o acesso ao trabalho, como se vê a seguir, no relato de um familiar:

ficou muito difícil, passamos apertado porque não dava pra trabalhar direito, [...] e cuidá dele, a mãe ajudava um pouco. [...] Sempre ficava assim vigiando ele, quando saía minha patroa, eu ficava vigiando ele, agora que a irmã dele veio morar (na casa), fica assim na mão dela e quando ela sai a gente vigia (Roberto, CA).

Neste sentido, Rosa (2003) refere que a necessidade de vigilância contínua está, muitas vezes, associada a um intenso nível de simbiose entre o cuidador e a pessoa com transtorno mental, assim como gera a cristalização de relações que colocam esta pessoa num lugar fixo e imutável de eterno dependente.

Os familiares referiram a dificuldade em compreender os comportamentos alterados de seus membros acometidos pela doença mental, o que parece causar um sofrimento psíquico intenso, em concordância com as atribuições da família apontadas por Rosa (2003) como "sofredora". A convivência com uma pessoa com transtorno mental (PTM) a influencia e, desse modo, a família precisa ser "tratada", assistida, ou seja, deve ser vista também como sujeito com necessidade de cuidados pelos profissionais de saúde. Do mesmo modo, a família ou familiar que cuida do PTM deve receber suporte social e assistencial já que assume a atribuição de "provedor(a) de cuidado".

ela não acha que eu sou mãe dela, quando ela fica doente, ela corta minha roupa de tesoura [...] ela não podia me ver que começava a jogar louça ni mim, ela dizia assim, conversava com gente de outro mundo, via padre voando, via freira.... (Madalena, MA).

A gente tinha muita dificuldade porque eu e meus irmãos tinha de conviver com ela daquele jeito, ela era nervosa, qualquer coisinha já brigava com a gente, né? [...] a gente ficava incomodado, a gente não compreendia muito bem... (Elis, C).

O transtorno mental é considerado um acontecimento complexo que envolve além do aspecto físico, os aspectos emocionais, culturais, sociais, e devido a esta complexidade, torna-se de difícil compreensão para a população em geral e sobretudo para a família que convive com a pessoa acometida pelo transtorno. Segundo Barroso et al. (2004), esta incompreensão provoca nos familiares um intenso sofrimento como algo que

se repete, se arrasta, desnorteia, desequilibra, tornando a relação complicada, sofrida, difícil de aceitar e conviver com a angústia de ter um doente mental na família [...]. Isso denota quão traumática é essa convivência, uma espécie de "cruz", que maltrata, machuca, deixa marcas não só no portador, mas também em seus familiares, como se a doença do outro causasse chagas nos familiares que acompanham de perto esse processo de adoecer. (p. 107).

\section{Mudanças no relacionamento familiar e extrafamiliar (parentes, vizinhos e amigos)}

A não compreensão do que ocorre com o familiar e de seus comportamentos faz emergir sentimentos diversos e mudanças no relacionamento de pessoas de sua rede social. No âmbito familiar, uma das mães refere sentir medo da filha até hoje: "Porque eu fiquei muito assustada porque ela disse que, assim, ela via chifre em mim, quando ela ficou alucinada ela disse que via chifre em mim [...] eu fiquei com muito medo..." (Madalena, MA).

De maneira geral, todos referiram alterações nas relações com os parentes, porém, nem todas, após o adoecimento do familiar. Um deles referiu indiferença dos mesmos: "Os parentes não ajudam, mas também, não atrapalham. Parente não tá nem aí, quem correu atrás dele fui eu, a mãe dele e agora a irmã que tá ajudando..." (Roberto, CA).

Outra familiar relatou que os parentes dela eram todos de outra cidade e os do marido afastaram-se após sua separação. Alguns referiram que os parentes já não eram "tão chegados" e com a doença do familiar, a situação piorou.

Com relação aos vizinhos, foram encontradas respostas tanto no sentido de ajudar, como de os vizinhos não perceberem alterações na casa porque o filho é quieto, até que os vizinhos fecharam as portas, porque perceberam movimento na casa: "Ela batia portas, gritava" (Madalena, MA).

Alguns marcam a não participação da vida social depois da doença. "Aqui de Botucatu, ninguém nunca mais nos convidou" (Madalena, MA). "O povo é todo afastado, o povo se afasta da gente, né? Mas eu não ligo” (Isaura, M).

Pelos depoimentos, pode-se constatar que os familiares, além das dificuldades de participar das atividades sociais e de lazer, às vezes, por cuidado com a pessoa com transtorno mental, também se sentem excluídos das relações sociais, muitas vezes não recebendo mais convites para eventos sociais, tendo os vizinhos, amigos e parentes afastados. Ao mesmo tempo, fica evidente que, apesar das mudanças, o isolamento da pessoa com transtorno mental não está resolvido. O movimento de mudança do modelo assistencial, com a proposta da extinção dos hospitais psiquiátricos, ainda em processo de construção, tem dificuldades para propor estratégias para lidar com os muros invisíveis da exclusão.

Nicácio (1989) aponta que, na medida em que o território se torna o ponto de partida da organização do cuidado, simultaneamente a comunidade (familiares, vizinhança, etc.) também deve se incluir nesse questionamento e se desinstitucionalizar. Uma perspectiva para a superação dessas dificuldades é a reorganização da atenção básica, em que a Estratégia de Saúde da Família (ESF) se estrutura tendo como base equipes multiprofissionais, que atuam a partir da adscrição e territorialização da população atendida, possibilitando a continuidade da atenção e a constituição de vínculos no processo de cuidado à saúde, tanto da PTM quanto da família ou familiar que assume o papel de "cuidador" (Dalla Vecchia \& Martins, 2009).

Neste sentido, Colvero, Ide e Rolim (2004) citam que dentre as diversas demandas apresentadas pelos familiares na convivência com a pessoa com transtorno mental, está a dificuldade em lidar com o isolamento social a que ficam sujeitos. 


\section{Avaliação da familia com relação à participação do usuário na AAC e expectativas com relação à ajuda}

Todos avaliaram que a participação do familiar na AAC foi positiva para os mesmos no sentido de terem uma ocupação, uma distração, terem responsabilidade, algo com que se preocupar, aprender coisas novas, terem iniciativa:

É bom porque se ele vem aqui (AAC), nós fica contente [...] Em casa ele só fica parado, quando ele fala que vai na Associação a gente se sente bem, sabe que ele vai sair, se distrair, não fica só em casa. (Roberto, CA)

Ela fica mais calma, ela chega em casa alegre, aprendeu coisas novas. Ela foi ganhando responsabilidade e nisso ajudou um pouco ela, agora cuida mais da casa, foi um jeito dela reagir. (Elis, C)

Mudou, bem, ele melhorou bastante, porque pelo menos ele vinha para cá, ele se arrumava e vinha. (Isaura, M)

Mudou bastante, porque de primeiro a Simone só ficava deitada, não via a luz do dia, ela tinha medo de ir até a porta da cozinha. (Madalena, MA)

Segundo Rosa (2003), a ocupação do tempo livre da pessoa com transtorno mental torna-se um dilema para o familiar cuidador, surgindo a necessidade de ocupar o seu tempo com uma atividade supervisionada que o entretenha, pois enquanto ele estiver ocupado, dispensa cuidado e vigilância, tranquilizando o mesmo, que sabe onde ele está e o que está fazendo.

Podemos pensar que os familiares estejam reproduzindo o modelo denominado por Costa-Rosa (2000) como modo asilar baseado nas práticas asilares tradicionais em que há pouca ou nenhuma consideração da existência do sujeito (como subjetividade desejante), o que implica não investir na sua participação ativa. Parece que o único lugar possível de existência para a pessoa com transtorno mental seja o de paciente, tutelado, distraído, ocupado, incapaz de ressignificar a sua vida e, consequentemente, o seu cotidiano.

Apenas uma das mães referiu que o filho quer trabalho remunerado. $\mathrm{Na} \mathrm{AAC}$, os usuários das oficinas geradoras de renda recebem uma bolsa de acordo com a participação, não caracterizando vínculo empregatício. Este usuário parece não se satisfazer mais com isso, segundo o relato da mãe, ele estava procurando emprego. Poder-se-ia pensar esta demanda como sendo um possível resultado do trabalho da AAC que, em última instância, visa à inclusão dos usuários no mercado de trabalho.

Com relação à necessidade de ajuda, todos foram categóricos em afirmar que ajuda financeira é o que eles mais precisam no momento, inclusive um deles, ao chegar à AAC, foi perguntando sobre a cesta básica que o filho recebia quando fazia tratamento em um dos serviços de saúde, e agora não estava mais frequentando e por isso perdeu o direito de receber. Outros depoimentos: "Em casa é só eu e o Caetano a gente passa um pouco de arrocho porque a aposentadoria minha é pouca, para pagar luz, gás, comprar comida, roupa e tudo" (Isaura, M).

Uma das mães, ao responder esta questão, emocionou-se, dizendo estar passando por muitas necessidades (tem uma filha e três netos residindo na mesma casa):

Eu tenho passado muita necessidade financeira, já até cortaram minha luz, eu tô devendo três meses, tô devendo a água dois meses, e tá muito difícil minha vida, até para comer, porque se fosse só eu e a Simone, dava para passar, mas tem os meus três netos que são pequenos, eles não querem saber se tem dinheiro pra comprar pão ou não (Madalena, MA).

O tratamento não apareceu como sobrecarga financeira, tendo em vista os usuários se tratarem nos serviços públicos de saúde mental do município, geralmente há vários anos. Estes serviços também oferecem quase toda medicação utilizada pelos mesmos, inclusive as de alto custo.

Cumpre ressaltar que os usuários deste estudo têm diagnóstico de transtorno mental grave, mas nenhum deles foi submetido à internação fechada no ano anterior e no ano da realização do mesmo. Frequentam a AAC há pelo menos um ano, ou a frequentaram por igual período e, antes disto, fizeram ou ainda fazem tratamento nos serviços de saúde mental. Isto demonstra que o processo de inclusão social envolve um investimento intenso e por longo prazo.

\section{Considerações finais}

Apesar das mudanças mais recentes na política pública na área de saúde mental brasileira, com um investimento importante na concretização de uma rede de serviços substitutiva ao hospital psiquiátrico, com ênfase na construção de uma atenção em rede, a legislação ainda está voltada para as pessoas que estiveram internadas no hospital psiquiátrico, como se pode notar na Lei 10.708 (De volta para a casa), que institui um auxílioreabilitação psicossocial para assistência de pacientes acometidos de transtornos mentais, egressos de internações (Ministério da Saúde, 2003). No entanto, existe uma população de pessoas com transtornos mentais graves que nunca passou por internação em hospital psiquiátrico e cujos cuidadores já faleceram. Estas pessoas encontram importantes dificuldades para se manterem na sociedade sem uma rede de suporte.

Esta pesquisa possibilitou o contato com um fragmento da realidade das famílias das pessoas com transtornos mentais graves que estão sendo tratadas nos serviços substitutivos e se perceber que elas sofrem, precisam de ajuda nos aspectos econômicos, emocionais, políticos e sociais, pois estão arcando com a maior parte da responsabilidade do cuidado dos usuários. Trata-se de uma população na sua maioria em condição de precariedade, que precisa lutar para garantir sua sobrevivência.

Os depoimentos serviram para ilustrar o fato de passarem necessidades e, muitas vezes, não conseguirem bancar a manutenção de uma casa. Isto fica evidenciado no caso de famílias com um só cônjuge, do sexo feminino, que passou a ser chefes de família, devido à separação ou viuvez. Pegoraro e Caldana (2008), que investigaram a ocorrência de sofrimento psíquico em familiares de usuários, concluíram que a sobrecarga recai sobre o cuidador e que geralmente as mulheres são mais afetadas.

Estas dificuldades são agravadas pela presença do usuário com transtorno mental em idade ativa que não consegue emprego 
e pelo fato de alguns deles necessitarem dos cuidados de um familiar que fica impossibilitado de trabalhar.

Estes dados evidenciam a urgência de atuação no grupo familiar para que o processo de desospitalização ocorra e que o cuidado do PTM não fique delegado quase exclusivamente à família, mas que a mesma possa receber subsídios (econômicos, culturais, pedagógicos, instrumentais) para lidar no cotidiano com o familiar com transtorno mental (Dalla Vecchia \& Martins, 2006; Rosa, 2003).

As entrevistas revelaram um sofrimento intenso dos familiares com relação a conviver com uma pessoa com transtorno mental; as dificuldades sofridas com a exclusão do convívio social devido ao afastamento das pessoas; solitárias para lidar com questões tão complexas, por exemplo, as dificuldades de traduzir e entender o sofrimento psíquico de seus familiares, que ficam com o comportamento muito diferente do que era antes, apresentando um mundo de sintomas, às vezes considerado assustador para a sociedade.

Pereira e Pereira Junior (2003) referem que, devido aos conflitos e desavenças surgidas quando o paciente é reinserido ou mantido no convívio social, os familiares solicitam ajuda, acolhimento e escuta, no sentido de amenizar a convivência com o mesmo. Ainda segundo estes autores

estar próximo do universo familiar significa estar em contato com realidades complexas e conflitantes que pedem uma assistência voltada à cooperação e à integração, uma vez que as expectativas dos familiares têm relação direta com as expectativas dos profissionais de saúde. (Pereira \& Pereira Junior, 2003, p. 99)

Nesse sentido, a partir dos resultados deste estudo, as estratégias de atuação com os familiares devem ser de oferecer grupos de apoio, baseados em escuta, solidariedade, compreensão e acolhimento. É importante também se criar estratégias que visem à participação delas em atividades de lazer promovidas pela AAC, para se aproximar mais das atividades que seu familiar realiza e para tentar aliviar o fardo do cotidiano.

Com a aproximação, a AAC poderá propiciar um lugar de reflexão e atuação política e social, por meio de ações que ajudem na organização dos usuários e familiares para que os mesmos possam ser parceiros do processo de construção e reivindicação de políticas sociais específicas para esta população.

As condições observadas e relatadas não são particularidades dos familiares pesquisados, mas expressa a realidade encontrada por grande parte das famílias que tem entre os seus membros uma pessoa com transtorno mental, conforme apontam outras pesquisas sobre o tema (Koga, 1997; Melman, 2001; Moreno, 2000; Ribeiro, 2003; Rosa, 2003).

Parece que a pessoa com transtorno mental, mesmo fora do manicômio, e sua família estão sendo punidos através da segregação e do estigma que elas ainda sofrem. Desta forma, é urgente que as políticas públicas na área não centrem as ações nos usuários, mas que possam incluir a família e suas relações com a pessoa com transtorno mental e com a rede de cuidado como prioridade, garantindo apoio psicossocial e cuidado integral. Além disso, faz-se necessário um trabalho educativo com a sociedade tanto por parte dos serviços de saúde, como de entidades como a AAC, no sentido de desconstruir idéias, paradigmas e valores vinculados à segregação, promovendo uma radical transformação da mentalidade, para que se possa romper de fato com a cultura manicomial.

\section{Referências}

Alves, D. S., \& Guljor A. P. (2004). O cuidado em saúde mental. In R. Pinheiro \& R.A. Mattos (Orgs.), Cuidado: as fronteiras da integralidade (pp. 221-240). São Paulo/ Rio de Janeiro: Hucitec.

Amarante, P. (1996). O homem e a serpente: outras histórias para a loucura e a psiquiatria. Rio de Janeiro: FIOCRUZ.

Amarante, P. (2000). Loucos pela vida: a trajetória da reforma psiquiátrica no Brasil. Rio de Janeiro: SDE/ENSP.

Associação Arte e Convívio (2006). Folheto de divulgação. Impresso.

Barroso, A. G. C., Abreu, L. M., Bezerra, M. A. A., Ibiapina, S. L. D., \& Brito, H. B. (2004). Transtornos mentais: o significado para os familiares. Revista Brasileira em Promoção da Saúde, 17(3), 99-108. Recuperado em 11 de março de 2009, de https://www.unifor.br/hp/doc_noticias/vol17-artigo1. pdf

Campaña, A. (1995). Salud mental: conciencia vs. seducción por la locura Quito: CEAS.

Colvero, L. A., Ide, C. A. C., \& Rolim, M. (2004). A família e doença mental: a difícil convivência com a diferença. Revista da Escola de Enfermagem da USP, 38(2), 197-205. Recuperado em 11 março de 2009, de http://www. ee.usp.br/reeusp/upload/pdf/112.pdf

Conselho Federal de Psicologia \& Ordem dos Advogados do Brasil. (2008). Relatório de Inspeção a Instituições de Longa Permanência para Idosos (ILPIs). Brasília: Autores.

Costa-Rosa, A. (2000). O modo psicossocial: um paradigma das práticas substitutivas ao modo asilar. In P. Amarante (Org.), Ensaio: subjetividade, saúde mental, sociedade (pp.141-168). Rio de Janeiro: FIOCRUZ.

Dalla Vecchia, M., \& Martins, S. T. F. (2006). O cuidado de pessoas com transtornos mentais no cotidiano de seus familiares: investigando o papel da internação psiquiátrica. Estudos de Psicologia, 11(2), 159-168.

Dalla Vecchia, M., \& Martins, S. T. F. (2009). Desinstitucionalização dos cuidados a pessoas com transtornos mentais na atenção básica: aportes para a implementação de ações. Interface - Comunicação, Saúde, Educação, 13(28), 151-164.

Ferreira, J. (2000). O projeto Axé - história e desafios. In A. M. B. Reis (Org.), Plantando axé: uma proposta pedagógica (pp. 25-46). São Paulo: Cortez.

Giovanella, L., \& Amarante, P. (1994). O enfoque estratégico do planejamento em saúde mental. In P. Amarante (Org.), Psiquiatria social e reforma psiquiátrica (pp. 113-148). Rio de Janeiro: FIOCRUZ.

Gonçalves, A. M., \& Sena, R. R. (2001). A reforma psiquiátrica no Brasil: contextualização e reflexos sobre o cuidado com o doente mental na família. Revista Latino-Americana de Enfermagem, 9(2), 48-55. Recuperado em 11 de março de 2009, de http://www.scielo.br/pdf/rlae/v9n2/11514.pdf

Kinoshita, R. T. (1996). Contratualidade e reabilitação psicossocial. In A. M. F. Pitta (Org.), Reabilitação psicossocial no Brasil (pp. 55-59) São Paulo: Hucitec.

Koga, M. (1997). Convivência com a pessoa esquizofrênica: sobrecarga familiar. Dissertação de mestrado não-publicada, Universidade de São Paulo, Ribeirão Preto.

Melman, J. (2001). Família e doença mental: repensando a relação entre profissionais de saúde e familiares. São Paulo: Escrituras.

Ministério da Saúde, Conselho Nacional de Saúde. (1996, 10 de outubro). Resolução no 196: Implementa as normas e diretrizes regulamentadoras de pesquisa envolvendo seres humanos. Brasília: Autor. 
Ministério da Saúde, Secretaria de Atenção à Saúde. (2003). Saúde mental e atenção básica: $o$ vínculo e o diálogo necessários. Recuperado em 2 de agosto de 2007, de http:/portal.saude.gov.br/portal/arquivos/pdf/diretrizes.pdf

Ministério da Saúde. (2008, 24 de janeiro). Portaria 154: Cria os Núcleos de Apoio à Saúde da Família - NASF. Diário Oficial [da] República Federativa do Brasil (pp. 47-50). Brasília: Autor.

Moreno, V. (2000). Vivência do familiar da pessoa em sofrimento psíquico. Tese de doutorado não-publicada, Universidade de São Paulo, Ribeirão Preto.

Nicácio, F. (1989). Da instituição negada à instituição inventada. In A. Lancetti (Org.), Saúde Loucura (pp. 91-108). São Paulo: Hucitec.

Pegoraro, R. F., \& Caldana, R. H. L. (2008). Sofrimento psíquico em familiares de usuários de um Centro de Atenção Psicossocial. Interface-Comunicação, Saúde, Educação, 12(25), 295-307. Recuperado em 11 de março 2009, de http://www.interface.org.br/ arquivos/aprovados/artigo47.pdf

Pereira, M. A. O., \& Pereira Jr., A. (2003). Transtorno mental: dificuldades enfrentadas pela família. Revista da Escola de Enfermagem da USP, 37(4), 92-100. Recuperado em 11 de março de 2009, de http://www.ee.usp.br/ reeusp/upload/pdf/158.pdf
Queiroz, M. I. P. (1988). Relatos orais: do “indizível” ao “dizível”. In O. R. M. von Simon \& M. I. P. Queiroz (Orgs.), Experimentos com histórias de vida (pp.14-43). São Paulo: Vértice.

Reis, J. R. T. (1994). Família, emoção e ideologia. In S. T. M. Lane \& W. Codo (Orgs.), Psicologia social: o homem em movimento (pp. 99-124). São Paulo: Brasiliense.

Ribeiro, M. B. S. (2003). Estudos de características familiares de usuários de uma associação civil para a reabilitação psicossocial. Dissertação de mestrado não-publicada, Universidade Estadual Paulista Júlio de Mesquita Filho, Botucatu.

Rosa, L. (2003). Transtorno mental e o cuidado na família. São Paulo: Cortez.

Souza, R. C., \& Scatena, M. C. M. (2005). Produção de sentidos acerca da família que convive com o doente mental. Revista Latino-Americana de Enfermagem, 13(2), 173-179. Recuperado em 11 de março de 2009, de http://www.scielo. br/pdf/rlae/v13n2/v13n2a07.pdf.

Souza, W. S. (2001). Associações civis em saúde mental no Rio de Janeiro: democratizando os espaços sociais. Cadernos de Saúde Pública, 17(4), 933-939.

1. Pesquisa financiada pela FAPESP.

2. São vários os termos utilizados para denominar o indivíduo que tem algum problema na área de saúde mental e que é usuário dos serviços de saúde nesta área: paciente com transtorno mental, louco, pessoa em sofrimento psíquico, entre outras. Optamos por utilizar pessoa com transtorno mental. Deste modo, no texto será sempre citado como tal, ou com a sigla PTM.

Marli Benedita Santos Ribeiro, mestre em Saúde Coletiva pela Faculdade de Medicina de Botucatu/ UNESP - Campus de Botucatu, SP, é coordenadora da área técnica de saúde mental na Secretaria Municipal de Saúde de Botucatu e professora do Curso de Terapia Ocupacional da Universidade do Sagrado Coração, Bauru, SP. Endereço para correspondência: Rua Dr. José Adriano Marrey Jr, 91; (Vila Padovan); Botucatu, SP; CEP: 18602-345. Fone: (14) 3881-1805; (14) 3811-1100. E-mail: marli.sr@uol.com.br

Sueli Terezinha Ferreira Martins, doutora em Psicologia Social pela Pontifícia Universidade Católica de São Paulo, é professora assistente no Departamento de Neurologia, Psicologia e Psiquiatria da Universidade Estadual de São Paulo (UNESP) - Campus Botucatu, SP. E-mail: sueliterezinha@yahoo.com.br Luiz Roberto de Oliveira, doutor em Saúde Pública pela Faculdade de Saúde Pública da USP, é professor no Programa de Pós-Graduação em Saúde Coletiva da Faculdade de Medicina de Botucatu / UNESP. E-mail: lunaoliv@uol.com.br 